\title{
Ein Organ sucht seine Funktion
}

_ Zu Beginn des neuen Jahres hat uns die medizinische Wissenschaft mit einer wahren Sensation aufgewartet. Wie bei dem berühmten Stern im Morgenland so wurde jetzt von Weisen aus dem Abendland, genauer gesagt aus Limerick in Irland, am Firmament der Organe ein neues entdeckt: das Gekröse. Es hat zwar keine so große Strahlkraft wie der Stern, der den drei Königen den Weg nach Bethlehem gewiesen hat, aber faszinierend ist die Sache schon.

Dass es so etwas wie das Gekröse gibt, wissen wir schon seit Studienzeiten. Aber dass diese simple Bauchfellfalte, die innere Organe einfach nur mit der Bauchwand verbindet, jetzt als Organ aufgewertet wurde, das hat sogar die Bildzeitung zu einer Meldung veranlasst. Bisher hatte dieses Gekröse nämlich ein eher unscheinbares Dasein im Bauchraum gefristet, den Chirurgen aber gelegentlich das Leben schwer gemacht, ansonsten allerdings kaum Beachtung gefunden. Das muss und wird sich jetzt ändern.

Doch was macht ein Organ eigentlich als solches aus? Reicht die eigenständige anatomische Topografie oder muss es eine wie auch immer geartete spezifische Funktion haben, wie jetzt gefordert wird? Über eine solche weiß man beim Gekröse bisher allerdings wenig, um nicht zu sagen gar nichts. Aber an funktionslosen Organen gibt es ja bereits einige im Körper. Dabei denke ich weniger an das Gehirn, auch wenn sich bei manchen Zeitgenossen diese Frage regelrecht aufdrängt. Der Blinddarm und die Gallenblase gehören dazu, ja es sind Organe, ohne die man gut, manchmal sogar bes- ser leben kann. Da wird auch nicht ständig gefragt, was diese Organe eigentlich machen. Warum also jetzt das Getöse ums Gekröse?

Doch beim Gekröse ist die Vermutung, schon wegen der räumlichen Nähe zum Darm, naheliegend, dass es der Sitz des viel zitierten Bauchhirns sein könnte. Und somit böte dieses lange Zeit vernachlässigte Organ die Möglichkeit, das zu behandeln, was mit Hilfe der anderen Organe bisher nicht überzeugend gelungen ist, nämlich das Übergewicht. Und wo ein neues Organ, da ein neuer Spezialist. Schon wird der Ruf nach einem neuen Fachgebiet, nämlich dem der „Gekrösologie“ laut. „Gekrösologe“ als $\mathrm{Zu}$ satzbezeichnung auf dem Praxisschild klingt ja auch nicht schlecht!

Dr. Peter Stiefelhagen

\section{Unheimliches Treiben unter der Haut}

\section{Befallswahn: Hier lohnt sich ein Drogentest}

\section{Dass Menschen mit Befalls- oder Der- matozoenwahn überdurchschnittlich häufig Drogen konsumieren, bestätigt eine britische Studie.}

_Es kribbelt und juckt, irgendetwas scheint sich unter der Haut zu bewegen. Obwohl sich objektiv kein Befund ergibt, vermuten Menschen mit Befallswahn, dass dort Parasiten ihr Unwesen treiben. In früheren Studien haben sich solche Patienten häufig als Drogen- oder Alkoholkonsumenten erwiesen. Eine Forschergruppe um Anthony Bewley vom Royal London Hospital hat dies in einem retrospektiven
Review bestätigt. Analysiert wurden die Daten von 86 Patienten im Alter von 23 bis 87 Jahren, die im Schnitt fünf Jahre lang an der Befallssymptomatik litten. Alle Teilnehmer waren nach eventuellem Drogenkonsum befragt worden. Bei 24 Patienten waren Urinproben untersucht worden.

Bei 22\% der Probanden wurde ein Drogenkonsum dokumentiert. 33\% der in den Urinproben durchgeführten Drogentests waren positiv. Am häufigsten war Cannabis konsumiert worden.

Die Londoner Wissenschaftler empfehlen, Patienten mit Befallswahn immer einen Drogentest anzubieten.

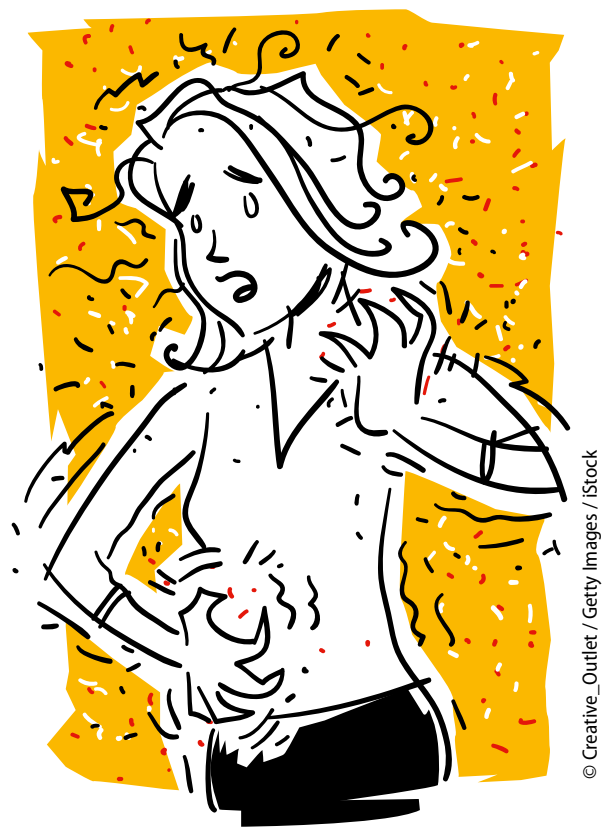

- Marshall C L et al. CED 2016; online 9. Dember 2016, DOI: 10.1111/ced.12999 